below that usually necessary to destroy the normal gland. If, therefore, myxoedema was related to radiotherapy, either the effect of irradiation was indirect or the thyroid glands were not normal initially.

That myxoedema was not a direct effect of irradiation is suggested by the finding of thyroid auto-antibodies in the serum of all five patients. Although only one antibody in low titre was found in each case, the serological findings were similar to those in "spontaneous" myxoedema, which is now generally believed to be of autoimmune origin (Owen and Smart, 1958 ; Roitt and Doniach, 1958 ; Doniach et al., 1960). It is reasonable to speculate, therefore, whether irradiation was a factor in the induction of an autoimmune reaction in these patients. There is no serological evidence that radiation can initiate an autoimmune reaction in the normal thyroid gland, nor did Irvine et al. (1962) find any correlation between the presence of auto-antibodies and the subsequent development of myxoedema in their thyrotoxic patients treated with ${ }^{131} \mathrm{I}$. On the other hand, Buchanan et al. (1962) found a higher incidence of microsomal antibody in patients treated with radioiodine than in those treated with antithyroid drugs, and Irvine (1963) and Doniach and Roitt (1963) found a frequent rise in the titre of thyroid antibodies during treatment with radioiodine.

Histological data on irradiated normal human thyroids are very scanty. Lindsay et al. (1954) found no evidence of Hashimoto's thyroiditis in five patients, four of whom were males, whose glands had been irradiated in the treatment of adjacent malignant disease, but obviously no conclusions can be drawn from such a small series. Although they found a high incidence of Hashimoto's thyroiditis in hyperplastic glands which had been treated with ${ }^{131} \mathrm{I}$ or with $x$ rays, these changes may have preceded irradiation.

It may be that the thyroids of the five patients (Cases 1-5) were not normal healthy glands, and that the malignant disease from which they were suffering may have rendered them susceptible to damage by radiation. An autoimmune reaction may thus have been initiated by the damage to the thyroid epithelial cells. An alternative possibility is suggested by the experiments of Roitt et al. (1962), who showed that in rats mild trauma by radioiodine or $x$ rays potentiated an inflammatory reaction to injected heterologous antithyroglobulin antibodies. Thus, if the thyroid glands in these patients were already the seat of focal thyroiditis, injury to the thyroid epithelial cells by radiation may have rendered them more susceptible to the action of thyroid auto-antibodies; or, alternatively, damage by antibodies may have sensitized the cells to the effect of radiation.

The apparent rarity of this complication may be explained by the greatly reduced life-span of patients suffering from diseases for which irradiation of the neck is required. Possibly minor damage to the thyroid may be more common than is realized, and screening of the glands, where appropriate, during deep $x$-ray therapy would be a simple and prudent precaution.

\section{Summary}

Five women suffering from malignant disease not arising from the thyroid gland developed myxoedema after therapeutic irradiation of the neck. The intervals between completion of radiotherapy and the diagnosis of myxoedema were 3 months, 5 months, 12 months (two patients), and 36 months respectively, and in all cases the thyroid gland was directly irradiated. The development of myxoedema, therefore, is believed to be related to radiotherapy.

The dose of radiation was far below that necessary to ablate the normal thyroid, and thyroid auto-antibodies in low titre were detected in all the patients. Myxoedema was unlikely, therefore, to have been a direct effect of radiation, and was probably mediated by an autoimmune reaction.

The possibility is discussed that the development of thyroid autoimmunity was related to irradiation of the gland.

We are indebted to Dr. M. A. C. Cowell and to Dr. E. R. Watson for referring Cases 4 and 5 to us, to Dr. J. B. Rennie for reading the script, and to Dr. J. M. Moore for performing the serological tests.

\section{REFERENCES}

Balfour, B. M., Doniach, D., Roitt, I. M., and Couchman, K. G. (1961). Brit. F. exp. Path., 42, 307.

Buchanan, W. W., Koutras, D. A., Crooks, J., Alexander, W. D., Brass, Endocr., 24, 115.

Doniach, D., Hudson, R. V., and Roitt, I. M. (1960). Brit. med. F., 1, 365

and Roitt, I. M. (1963). Clinical Aspects of Immunology, edited by P. G. H. Gell and R. A. Coombs, p. 626. Butterworth, London.

Félix, H., Dupré, N., Drape, M., and Court, L. (1961). Lyon méd., 206, 1043 .

Goolden, A. W., and Davey, J. B. (1963). Brit. 7. Radiol., 36, 340.

Green, M., and Wilson, G. M. (1964). Brit. med. F., 1, 1005.

Groover, T. A., Christie, A. C., Merritt, E. A.., Coe, F. O., and McPeak, E. M. (1929). F. Amer. med. Ass., 92, 1730.

Irvine, W. J. (1963). Symposium on the Thyroid and its Diseases. Royal College of Physicians, London.

- Macgregor, A. G., and Stuart, A. E. (1962). Lancet, 2, 843.

Lindsay, S., Dailey, M. E., and Jones, M. D. (1954). F. clin. Endocr., 14,1179 .

Owen, S. G., and Smart, G. A. (1958). Lancet, 2, 1034

Roitt, I. M., and Doniach, D. (1958). Ibid., 2, 1027.

- Jones, H. E. H., and Doniach, D. (1962). Reports of 2 nd International Congress on Immunopathology, Kalamazoo 1961, edited by P. Grabar and P. B. Miescher Schwabe, Basle.

Warren. S. (1943). Arch. Path., 35, 304.

\title{
Carbachol and Vitamin $\mathbf{B}_{12}$ Absorption
}

\author{
A. W. DELLIPIANI,* M.B., CH.B., M.R.C.P.ED. ; D. A. SEATON,* M.D., M.R.C.P.ED., M.R.C.P.GLASG., D.OBST.R.C.O.G.
}

Impaired absorption of vitamin $\mathrm{B}_{12}$ is known to occur in a considerable proportion of patients who have had partial gastrectomy (Adams, 1958 ; Deller, Richards, and Witts, 1962) and is almost always the result of deficiency of intrinsic factor (Herbert, 1959). The administration of carbachol has been found to increase vitamin- $B_{12}$ absorption except in patients

\footnotetext{
* University Department of Therapeutics, the Royal Infirmary, Edin-
} bargh. with pernicious anaemia (Baker and Mollin, 1955; Mollin, Booth, and Baker, 1957) and should therefore increase absorption in patients with partial gastrectomy unless there is complete atrophy of the gastric remnant or secretion is already maximally stimulated. However, Ardeman, Chanarin, and Doyle (1964) have been unable to demonstrate increase of intrinsic-factor secretion after administration of carbachol to eight " normal" subjects. Carbachol is, however, often used in tests of vitamin- $B_{12}$ absorption in the belief that the test is then more 
reliable. The results of the present study, which was originally an investigation on patients with partial gastrectomy only, are presented in brief as they are of interest in relation to the use of carbachol in Schilling tests.

\section{Methods and Materials}

There were three groups of patients: (1) nine hospital controls who were not anaemic and had no known haematological or absorptive defect; (2) three patients with proved and treated pernicious anaemia ; (3) eight random patients who had had partial gastrectomy, carried out from three to fifteen years previously.

Schilling Tests.-The Schilling (1953) tests were carried out at intervals of three to seven days, the usual interval being seven days, and were performed alternately with and without carbachol. After overnight fasting the patients were given $0.25 \mathrm{mg}$. of carbachol by intramuscular injection followed 15 minutes later by an oral dose of $0.5 \mu \mathrm{g}$ of ${ }^{58} \mathrm{Co}$-vitamin $\mathrm{B}_{12}$ in $10 \mathrm{ml}$. of water; $100 \mathrm{ml}$. of water was added to the empty container, mixed round, and drunk by the patient to ensure as complete as possible ingestion of the radioactive vitamin $B_{12}$. Urine was collected for 24 hours after the injection of vita$\min \mathrm{B}_{12}$; the volume was made up to two litres with water and then counted for its radioactivity content.

\section{Results}

The results are shown in the Table. There is no significant difference between the results of the tests with and without carbachol for all the patients investigated or for any of the groups. The levels of excretion for all groups are in keeping. with those recorded by other workers.

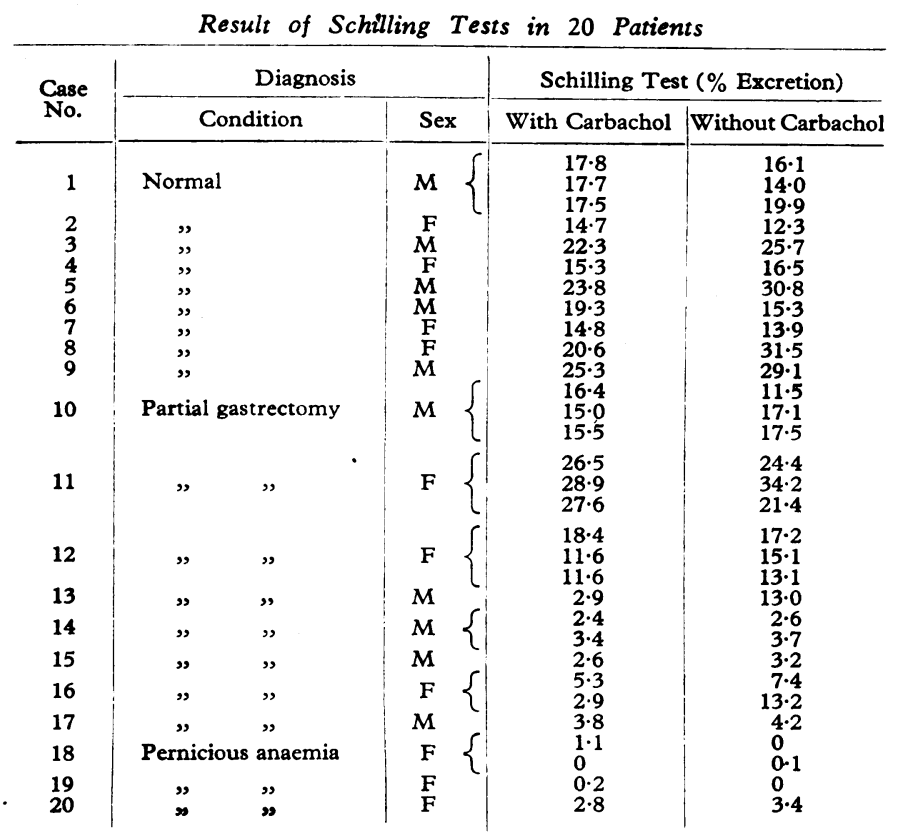

\section{Comment}

If impaired absorption of vitamin $B_{12}$ after partial gastrectomy is the result of deficiency of intrinsic factor, this may be due to (1) lack of secreting area, (2) gastritis or atrophy of the gastric remnant (Deller, Richards, and Witts, 1962), or (3) episodic lack of secretion of intrinsic factor (Adams and Cartwright, 1963).

On the assumption that carbachol stimulates intrinsic-factor secretion and consequently vitamin- $B_{12}$ absorption it is possible to determine the mechanism of deficiency more precisely: if there is insufficient secreting area or episodic secretion then vitamin- $B_{12}$ absorption should be increased after carbachol administration unless the gastric remnant is already secreting maximally. However, the work of Ardeman et al. (1964) failed to demonstrate any increase in intrinsic-factor secretion of various patients after carbachol.

In the present study the use of carbachol did not increase vitamin- $\mathrm{B}_{12}$ absorption, as determined by the Schilling test, in patients who had had a partial gastrectomy. The investigation was therefore extended to normal subjects and to patients with pernicious anaemia. Even in normal subjects, however, absorption was not increased by use of carbachol.

At first sight these results seem to support the findings of Ardeman et al. (1964) that carbachol does not increase intrinsicfactor secretion. The original work showing increased absorption of vitamin $B_{12}$ after carbachol administration (Baker and Mollin, 1955 ; Mollin et al., 1957) was, however, carried out by means of faecal-excretion tests, which provide a more accurate quantitative assessment of vitamin- $\mathrm{B}_{12}$ absorption than does the Schilling test. The results of the present study show that absorption of vitamin $\mathrm{B}_{12}$ as determined by the Schilling test is not enhanced by administration of carbachol. There is therefore no advantage in using carbachol in the Schilling test, and this practice should be abandoned, particularly as side-effects are common and may be disturbing to the patient.

\section{Summary}

A study was made of the influence of carbachol on vitamin- $\mathrm{B}_{12}$ absorption as assessed by Schilling tests on nine hospital controls, three patients with pernicious anaemia, and eight random patients who had had partial gastrectomy performed.

No significant difference was found in the results of the tests with and without carbachol for all the patients investigated or for any of the three groups.

There seems to be no advantage in using carbachol in the Schilling test, and it is suggested that this practice be abandoned.

We wish to thank Professor R. H. Girdwood, Dr. J. H. Croom, and Dr. J. S. Robson for allowing us to study patients under their care; also Mr. R. Samson and Mrs. E. Skedd for technical assistance and Mr. P. Kinnear for statistical analysis.

\section{RRFBRENCES}

Adams, J. F. (1958). Gastroenterologia (Basel), 89, 326.

- and Cartwright, E. June (1963). Gut, 4, 32.

Ardeman, S., Chanarin, I., and Doyle, J. C. (1964). Brit. med. ₹., 2, 600.

Baker, S. J., and Mollin, D. L. (1955). Rev. Hémat., 10, 180. Deller, D. J., Richards, W. C. D., and Witts, L. J. (1962). Quart. 7.
Med., 31, 89.

Herbert, V. (1959). The Megaloblastic Anaemias. Grune and Stratton, New York.

Mollin, D. L., Booth, C. C., and Baker, S. J. (1957). Brit. F. Hacmat., 3,412 .

Schilling, R. F. (1953). f. Lab. clin. Med., 42, 860. 